\title{
NO EXISTEN MAPAS PARA ESTOS TERRITORIOS: RUBÉN MARTÍN (DÍAZ) Y LA TOPOGRAFÍA ESTÉTICA DE LA POESÍA ESPAÑOLA RECIENTE
}

Maps for these territories don’t exist: Rubén Martín (Díaz) and the aesthetic topography of recent Spanish Poetry

\author{
PAUL CAHILL \\ Pomona College, Claremont, CaLifornia (ESTAdos unidos) paul.cahill@pomona.edu
}

RECIBIDO: 3 DE ENERO DE 2018

ACEPTADO: 18 DE MAYO DE 2018

RESUMEN: Partiendo de la premisa que el mundo poético español actual no es un espacio discursivo neutro abierto a toda aproximación textual este estudio traza las estrategias estéticas de dos poetas españoles contemporáneos cuyos nombres similares—Rubén Martín Díaz (1980) y Rubén Martín (1980) — nos obligan a ir más allá de la firma literaria y adentrarnos en las propuestas de escritura que caracterizan su quehacer poético. Aunque la obra de cada poeta establece un diálogo sugerente con muchos de los mismos conceptos—la mirada, el mundo natural, el yo y el lenguaje—su modo de concebir estos conceptos y su interacción compleja es diferente. En el caso de cada poeta se estudian textos ecfrásticos al lado de otros textos que, juntos, ofrecen una visión de la actitud de cada propuesta de escritura hacia el mundo fragmentado en el que vivimos. Esta exploración nos provee una imagen más clara de las posibilidades estéticas de la poesía española actual y su relación con la tradición literaria española. Aunque este trabajo sólo se enfoca en la obra de estos dos poetas también busca situar su obra en el contexto más amplio de la poesía española actual.

PALABRAS CLAVE: écfrasis, forma(s) poética(s), lenguaje, naturaleza, realidad.

ABSTRACT: Building from the premise that the world of contemporary Spanish poetry is not a neutral discursive space open to all textual approaches, this study will trace the aesthetic strategies employed by two contemporary Spanish poets whose similar names-Rubén Martín Díaz (1980) and Rubén Martín (1980) — require us to look beyond the authors' signatures and immerse ourselves in the textual approaches that characterize their poetic projects. Although the work of each poet establishes a compelling dialogue with many of the same concepts - the gaze, the natural world, the $I$, and languageits way of conceiving of these concepts and their complex interaction differs. In the case of each poet we will study ekphrastic texts alongside other texts, which, together, offer a vision of each textual approach's attitude towards the fragmented world in which we live. This exploration will provide us with a clearer picture of the aesthetics of Contemporary Spanish Poetry and its relationship with past Spanish literary traditions. Although this study only focuses on the work of these two poets it also seeks to situate their work in the larger context of current Spanish poetry.

KEYWORDS: ekphrasis, language, nature, poetic form(s), reality.

Cahill, Paul.

"No existen mapas para estos territorios: Rubén Martín (Díaz) y la topografía estética de la poesía española reciente". Kamchatka. Revista de análisis cultural 11 (Julio 2018): 127-144

DOI: 10.7203/KAM. 11.11325 ISSN: 2340-1869

Monográfico LECTURAS DEL DESIERTO: NUEVAS PROPUESTAS POÉTICAS EN ESPAÑA 


\section{¿LA CONVIVENCIA SOSEGADA?}

En su prólogo a Re-generación. Antología de poesía española (2000-2015) (2016), José Luis Morante describe el momento poético actual como uno en el que las viejas escuelas y etiquetas ya no dominan o determinan la producción poética española, porque según él:

[n] os hallamos ante la convivencia sosegada de idearios, un espacio en marcha que siembra en cada taller la esperanza del fruto singular. Se han superado monopolios estéticos, no hay camisas de fuerza ni limitaciones programáticas y los poemas en red cuentan con una repercusión cosmopolita e instantánea (Morante, 2016: 12).

Pero incluso en una época marcada por la posibilidad de acceder a la producción poética a través de internet, las nuevas voces poéticas suelen darse a conocer mediante vías tradicionales como antologías y por la publicidad y visibilidad que viene con ganar premios importantes y ser reseñado en publicaciones de alcance nacional. Además de antologías importantes para la poesía más reciente como la de Morante y Nacer en otro tiempo. Antología de la joven poesía española (2016), otra antología particularmente importante para la poesía española reciente fue Poesía ante la incertidumbre: Antología (Nuevos poetas en español) (2011). La publicación de esta selección de la obra de ocho poetas nacidos entre 1973 y 1982 que escriben en español (no sólo en España sino también en Argentina, Colombia, El Salvador, México y Nicaragua) causó una polémica de la cual surgió una "Carta abierta en defensa de la pluralidad y convivencia de poéticas". Esta polémica tuvo que ver tanto con la selección en sí como con el prólogo que la encabeza. "Defensa de la poesía”, el prólogo a esta antología, comienza con la siguiente declaración:

El momento de la Historia que nos ha tocado vivir está marcado por la incertidumbre en todos los sentidos. Cuando pensábamos que el siglo XX agonizaba y con él los grandes temores y catástrofes capaces de minar la fe en la humanidad, no han surgido los puentes que destruyan nuestros precipicios. Al contrario, resulta más difícil intuirlos, imaginarlos. La incertidumbre parece abarcarlo todo: la política, la moral, la economía, las nuevas formas de comunicación que paradójicamente han provocado una mayor incomunicación... También las viejas utopías que parecieron realizables y llenaron de ilusión a millones de ciudadanos se han desmoronado mostrando sus miserias cuando han sido suplantadas por los hombres, añadiendo aún más incertidumbre a todo lo que nos rodea (2011: 7).

El próximo párrafo de esta nueva "Defensa de la poesía" ofrece una reacción generacional a esta incertidumbre, explicando que "[n]uestra generación está marcada por esta incertidumbre y creemos que es necesario hacer un alto en el camino, reflexionar, mirarnos a los ojos, establecer una cercanía menos artificial, más humana. La poesía puede arrojar algo de luz para alcanzar algunas certidumbres necesarias" (2011: 7). La postura de esta selección de "poesía ante la incertidumbre" consiste en intentar restablecer la certidumbre en vez de explorar o aceptar la incertidumbre como elemento constitutivo de la modernidad.

La meta de "arrojar luz" también forma parte del proyecto de Nacer en otro tiempo, la antología de Miguel Floriano y Antonio Rivero Machino. Esta colección tiene "el objetivo de bosquejar un mapa que aproxime cabalmente al lector a nuestra joven poesía y, al tiempo, arrojar un poco de luz sobre esa actual diáspora de autores activos, caótica de tan vasta" (Floriano y 
Rivero Machina, 2016: 225) y busca trazar "un somero atlas de los distintos tipos de poesía que están escribiendo hoy los jóvenes poetas" (Floriano y Rivero Machina, 2016: 226). Hasta cierto punto este proyecto respeta la autonomía de los textos, ya que este "mapa" y "atlas" aparece después de los poemas en sí, como parte de un epílogo, lo cual deja que los propios poemas hablen con voz propia. Pero como cualquier intento de representar un fenómeno tan complejo como la práctica poética de una época, no se puede lograr de manera objetiva.

El mapa/atlas en este caso se construye a partir de cierta visión de cómo debe ser y cómo debe funcionar un poema, ya que los antólogos llevan a cabo su tarea "conscientes de que el poema se concibe inevitablemente- $\mathrm{O}$ al menos así lo concebimos nosotros-como una microestructura textual que no da pie a demasiadas mutaciones o innovaciones en la modalización del discurso literario y, por ende, tampoco a una autonomía netamente aséptica del estilo" (Floriano y Rivero Machina, 2016: 226).

Además de depender de una visión limitada de lo que es un poema el epílogo de Floriano y Rivero Machina también traslada conceptos y prejuicios de conflictos estéticos anteriores al momento actual como la crítica de la vanguardia ("el prurito rupturista de las vanguardias del siglo XX”) y la crítica de los novísimos ("la arrogancia culturalista de la mención por la mención”) (Floriano y Rivero Machina, 2016: 227).

Incluso en instancias en las que no se usan etiquetas como la poesía de la experiencia, la poesía novísima o la poesía del silencio, todavía existe en el siglo XXI-y ha existido a lo largo del siglo XX-una tensión conflictiva entre vertientes poéticas figurativas y no figurativas (o menos figurativas). La persistencia de esta tensión se puede notar si hacemos un brevísimo recorrido de polémicas entre poetas y críticos como la que hubo entre la visión de la poesía como comunicación o conocimiento, entre los novísimos y los poetas de la experiencia y hasta entre éstos últimos y poetas más recientes como Antonio Méndez Rubio (y otros miembros del Colectivo Alicia Bajo Cero), Benito del Pliego, Marta Agudo y Marcos Canteli, entre otros. Si la vertiente figurativa ha tenido representantes tan visibles como Luis García Montero y precursores como su versión de Luis Cernuda y Jaime Gil de Biedma, también se podría trazar una tradición alternativa establecida por poetas como Francisco Pino, Juan Eduardo Cirlot, Antonio Gamoneda, José-Miguel Ullán, Aníbal Núñez, Leopoldo María Panero, Olvido García Valdés, Chantal Maillard, Miguel Casado y Juan Carlos Mestre. El ambiente de la poesía española actual, entonces, no consiste en "la convivencia sosegada de idearios", sino en un espacio discursivo conflictivo en el cual conceptos como la (in)certidumbre, la mímesis y el papel que juega el lenguaje con respecto a la representación de la realidad se debaten y se exploran de diferentes maneras en la práctica poética española actual.

\section{“RUBÉN MARTÍN”, O EL RESBALADIZO TERRENO DE UN NOMBRE}

Las páginas que siguen se aprovechan de una arbitrariedad inicial para trazar y explorar dos propuestas de escritura divergentes en la poesía española actual. La serie de libros publicados entre 2007 y 2016 bajo el nombre de Rubén Martín—o Rubén Martín Díaz-exhibe una mezcla de estilos tan diferentes que dan la impresión de corresponder a diferentes poetas. 
Rubén Martín nació en 1980, pero en realidad se trata de dos poetas, los dos nacidos en 1980, en lugares diferentes (Rubén Martín Díaz en Albacete y Rubén Martín en Granada) ${ }^{1}$. Esta suerte de rompecabezas autoral ha creado tanta confusión que hasta algunas bibliotecas han atribuido las publicaciones de estos dos poetas al autor equivocado. En su ensayo significativo sobre "la publicidad como fuente historiográfica", Jenaro Talens hace hincapié en la tensión entre el "resbaladizo terreno de los nombres" y "el análisis de las propuestas de escritura" (Talens, 1989: 17). El primer enfoque correspondería a "la tendencia, nunca discutida, a periodizar y abordar el fenómeno literario tomando como punto de referencia la noción de autor, en tanto propietario privado del sentido de los textos" (Talens, 1989: 2), mientras que el segundo se enfocaría más en el trabajo discursivo que un texto propone y hace.

El caso de Rubén Martín (Díaz) nos obliga a enfocarnos en las propuestas de escritura de cada texto suyo, ya que un enfoque en el nombre no sirve para dar cuenta de lo que hace cada texto. Un análisis de estas propuestas de escritura también ofrece una buena oportunidad para ver algunas de las prácticas y posibilidades estéticas en la actualidad además de la relación entre estas prácticas y la poesía española del siglo XX.

Según Margaret H. Persin, "poetic texts presuppose certain theoretical, ideological, and discursive issues for the reader" (Persin, 1997: 13). El enfoque de su estudio Getting the Picture: The Ekphrastic Principle in Twentieth-Century Spanish Poetry es la poesía ecfrástica y para ella este tipo de poesía revela mucho sobre el proyecto estético de un/a escritor/a, ya que "poetic texts of this type [...] bring to the forefront a series of issues which bear directly upon the reading-and writing-process, and reveal a poet's choices, propensities, and philosophical as well as ideological postures that perhaps could only be surmised in a less explicit fashion from a reading of texts that are not ekphrastic" (Persin, 1997: 13). La poesía ecfrástica, entonces, nos ofrece una oportunidad idónea para adentrarnos en los supuestos estéticos en los cuales se basan los textos de estos dos poetas.

Un concepto clave para cualquier aproximación a la écfrasis es la mímesis. En sus estudios sobre la poesía de Guillermo Carnero y Ada Salas respectivamente, Juan José Lanz y Carmen Morán Rodríguez apelan al concepto de "una doble mímesis", "puesto que el texto ecfrástico representa con palabras una representación plástica" (Lanz, 2012: 113) y porque "en ella se imita mediante palabras una realidad que es, a su vez, otra mímesis (pictórica, por ejemplo) de la realidad natural” (Morán Rodríguez, 2012: 166-67). Estos tratamientos de la mímesis se basan en una visión optimista de ella—tanto verbal como visual. Una actitud más crítica hacia este fenómeno propondría la siguiente pregunta: ¿qué pasaría con la representación verbal de una mímesis inicial que no es tan mimética o es anti-mimética?

En su discusión de la écfrasis W. J. T. Mitchell emplea como punto de partida la imposibilidad de la representación verbal de lo visual, explicando que este tipo de figuración "[p]uede referirse a un objeto, describirlo, invocarlo, pero nunca puede brindar su presencia visual ante nosotros al igual que lo hacen las imágenes" (Mitchell, 2009: 138). Esta imposibilidad da pie a una serie de reacciones, entre ellas la "esperanza ecfrástica" y el "miedo ecfrástico".

1 Otro Rubén Martín, Rubén Martín Giráldez (Cerdanyola del Vallès, 1979), es novelista y traductor. 
La primera, "la «esperanza ecfrástica»", "es la fase en la que la imposibilidad de la écfrasis se supera con la imaginación o la metáfora, cuando descubrimos que existe un «sentido» en que el lenguaje puede hacer aquello que muchos escritores han querido hacer: «hacernos ver»" (Mitchell, 2009: 138). "Una vez que el deseo de superar la «imposibilidad» de la écfrasis entra en juego", explica Mitchell, "las posibilidades y expectativas puestas en la representación verbal de las representaciones visuales se vuelven casi interminables" (Mitchell, 2009: 139).

En el "miedo ecfrástico", en cambio, "todos los objetivos de la «esperanza ecfrástica» [...] se convierten en siniestros y peligrosos" y "[t]odas las aspiraciones utópicas de la écfrasis [...] comienzan a parecer idólatras y fetichistas. $\mathrm{Y}$ las figuras utópicas de la imagen y de su presentación textual como ventanas transparentes hacia la realidad quedan reemplazadas por la idea de la imagen como una ilusión engañosa, una técnica mágica que amenaza con fijar al poeta y al que escucha" (Mitchell, 2009: 141).

Estas dos reacciones hacia la imposibilidad de la écfrasis conducen a diferentes tipos de poesía. Una actitud más optimista se observa en la definición de la écfrasis que Juan José Lanz ofrece según la cual ésta "es un artificio retórico en el que un medio del arte trata de referir a otro medio mediante la definición y descripción de su forma o de su esencia, otorgando de este modo una mayor vivacidad a lo representado, mediante su representación imaginativa" (Lanz 2012: 112). Murray Krieger usa este término "para denotar un "principio» general que ejemplifica el lenguaje estetizante de lo que él llama el «momento detenido». [...] El objetivo de este tipo más general de écfrasis no es sólo la visión, sino el estatismo, la forma, la clausura y la presencia silenciosa" (Mitchell, 2009: 139). A pesar del contraste aparente entre "una mayor vivacidad” y "el momento detenido", ambas visiones de la écfrasis les atribuyen un poder importante a la escritura y el lenguaje.

Otro concepto clave para la aproximación a la écfrasis es la alteridad. Según Mitchell "[e]1 objetivo central de la esperanza ecfrástica podría llamarse «la superación de la alteridad». La poesía ecfrástica es el género en el que los textos se encuentran con sus «otros» semióticos, esos modos de representación rivales y extraños, que llamamos artes visuales, gráficas, plásticas o «espaciales»" (Mitchell, 2009: 141). La meta de "superar la alteridad" nos hace pensar en "los puentes que destruyan nuestros precipicios" anhelados por el/la autor/a anónimo/a de la "Defensa de la poesía" que encabeza Poesía ante la incertidumbre. Una actitud más crítica ante la écfrasis y la certidumbre seguiría otro camino y vería esta alteridad como un aspecto positivo o productivo.

Lanz describe dos tipos de diálogo o encuentro entre poesía y pintura. Por un lado hay "poemas en que las técnicas pictóricas están estrechamente relacionadas con las características del estilo o con la técnica de elaboración poética del autor" (Lanz 2012: 114), mientras que "[p]or otro lado, estarían aquellos poemas a los que la pintura proporciona temas concretos: algunos textos son glosa de pinturas concretas; el estilo de determinados artistas o escuelas se intenta reproducir en el texto poético; desde el texto poético se reflexiona sobre algún aspecto del arte de la pintura" (Lanz, 2012: 114-15). Los poemas de Rubén Martín Díaz y Rubén Martín que analizaremos a continuación exhibirán una mezcla de estas características, además de dos actitudes hacia la écfrasis, la mímesis y la alteridad. 
Este estudio se enfocará en Arquitectura o sueño (2015) de Rubén Martín Díaz y Sistemas inestables (2015) de Rubén Martín, usando cada libro como ejemplo de una apuesta estética en el terreno actual de la poesía española. En el caso de cada poeta analizaremos una serie de poemas ecfrásticos que establecen un diálogo con la poética y visión de otros artistas antes de pasar a una discusión más específica de su obra y cómo concibe y presenta la relación entre el yo poético, el lenguaje y la realidad.

\section{RUBÉN MARTÍN DÍAZ: ORDEN Y SILENCIO}

La poesía de Rubén Martín Díaz ha ganado una serie de premios, entre ellos el Premio Nacional de Poesía Fundación Siglo Futuro-Caja de Guadalajara (Contemplación, 2009), el Premio Adonáis y el Premio Ojo Crítico de RNE (El minuto interior, 2010), el Premio de Poesía Hermanos Argensola (El mirador de piedra, 2012) y el Premio Internacional de Poesía Barcarola (Fracturas, 2016). Su poesía exhibe huellas del legado de poetas como Jorge Guillén y Claudio Rodríguez. "Sugestión", uno de los poemas de El minuto interior, ofrece un ejemplo particularmente claro del legado guilleniano en la poesía de Martín Díaz cuando explica que:

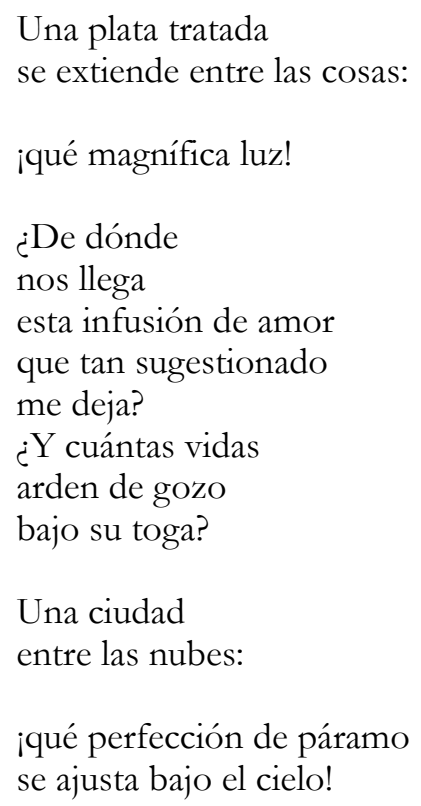

¡Qué mezcla de metales en la luz! (Martín 2010: 42, vv. 1-16).

Una visión semejante de la plenitud y la capacidad del lenguaje y el arte de captarla se encuentra en una serie de poemas que pertenecen al libro titulado Arquitectura o sueño (2015). La colección usa un epígrafe de Pere Gimferrer como marco para una serie de poemas en prosa que tienen como trasfondo una visita a París. Como ha señalado José Luis Morante, el tratamiento metapoético del proceso de creación artística aparece en muchos de estos poemas: "[u]sando como formato el poema en prosa, Arquitectura o sueño propicia una indagación en el limo nutricio de la escritura" (Morante, 2016: 14). En dos casos especialmente notables se usan representaciones ecfrásticas de obras plásticas como vehículo para la metapoesía. Tanto "La Gran 
Odalisca" como "El grito de Munch" emplean una aproximación personal para enmarcar un análisis de cada obra y su significado para la creación artística en general.

El comienzo de "La Gran Odalisca" explica por qué al yo poético no le convence esta obra de Jean Auguste Dominique Ingres (1780-1867), aclarando que "No es que me sea ingrato su desnudo, la amplia curva de su espalda o sus nalgas disipadas bajo niebla", sino que "es simplemente que el retrato niega lo que el ojo ve" (19). El texto continúa con una discusión de lo que esta obra no hace: "La irrealidad disimulada en un aspecto femenino-acaso destrucción de un orden en el cuerpo de mujer-no pondera la materia carnal ni un deseo revelado" (19). Estos tres elementos-el cuerpo de mujer, la materia carnal y un deseo revelado-hacen hincapié en el contenido y el fondo de la obra, al igual que los elementos mencionados en la primera oración del poema. En vez de enfocarse en estos elementos temáticos, sin embargo, la voz poética asevera que Ingres tiene otra meta: "Es, más bien, el hecho por el hecho lo que Ingres busca conseguir. La pintura, sin más motivo ni razón. Solo pintura” (19).

Para el hablante de este poema esta meta, "La pintura, sin más motivo ni razón. Solo pintura" no es suficiente. Para éste hay que prestar atención al contenido de la obra y específicamente el contenido que tiene una conexión fuerte y clara con lo humano. Ver la obra de Ingres de este modo requiere un concepto estable de la realidad ("lo que el ojo ve") además de una fe en el orden y en la mímesis. Aquí se observa una especie de "doble mímesis" curiosa, ya que el discurso metapoético y meta-artístico no acepta la representación inicial tal cual sino que la interroga.

"El grito de Munch" presenta una perspectiva parecida a la que se elabora en "La Gran Odalisca" y en el segundo párrafo del poema el hablante no acepta la visión impuesta por el pintor: "Lo que vi al contemplar el cuadro por primera vez no fue el arte por el arte del autor, su destreza en el manejo de una disciplina, sino su propio fondo desmembrado sobre el lienzo, su verdad absoluta. Una obra maestra al servicio del hombre" (33).

El primer párrafo del poema relata la reacción del hablante ante este cuadro icónico y aunque esta narración emplea el imperfecto y el pretérito, son los verbos en el pretérito los que establecen el ritmo que marca esta experiencia estética: "Reventó la tarde un grito exasperado. El cielo, antes teñido de malva, quedó envuelto en un sinuoso e irreal escupitajo carmesí. El río, que parecía manar de la boca del propio Munch, vertió sus aguas añiles en las cuencas de mis ojos. Y quedé abrazado a esa voz ornamental en una pira de sueños" (33).

Lo que se transmite mediante la obra de Munch es un contenido bien humano: "La tétrica apariencia del pintor-con sus dos colegas postrados tras de él, hacia el final del puente, como sombras de una ausencia que apenas se pronuncia-representa la semilla incolora del dolor, la espina clavada por la mano del padre en el centro exacto de su niñez" (33). La significación en esta oración sigue un camino bastante directo, ya que la esencia de la frase se basa en una relación causal clara entre "la tétrica apariencia del pintor" que "representa la semilla incolora del dolor" y es recibida por el yo poético, porque "[a]l contemplar la imagen, algo de esa herencia penetró en mí” (33). El resto del primer párrafo del poema consiste en una continuación de la descripción del impacto de la obra en el yo poético: "Sentí el marco y la náusea convocar un fuego insano bajo la piel habitada. Pero, tras de ese bosque hecho astillas, una vez tocado fondo en el dolor, la 
crecida de la luz no se hizo esperar. Y entré, algo convulso, en un estado de armonía, en un remanso de paz totalizada" (33). Si volvemos al segundo párrafo del poema entenderemos mejor la importancia y primacía del fondo humano frente al artificio artístico que expresa este fondo humano. Tanto "La Gran Odalisca" como "El grito de Munch" enfatizan el fondo y el significado en vez de la forma y el significante. El enfoque metapoético y artístico de cada texto traza un mundo conceptual en el que la forma artística (y poética) sólo sirve como pretexto para la representación de "la tétrica apariencia del pintor" y "lo que el ojo ve".

Una exploración de la relación entre fondo, forma, yo poético y mundo natural también aparece en textos de Martín Díaz que no establecen un diálogo explícito con otras obras de arte. Una serie de estos poemas postula una conexión entre el silencio, el yo poético y el mundo natural. "Fuente nacimiento" de El minuto interior nos explica que:

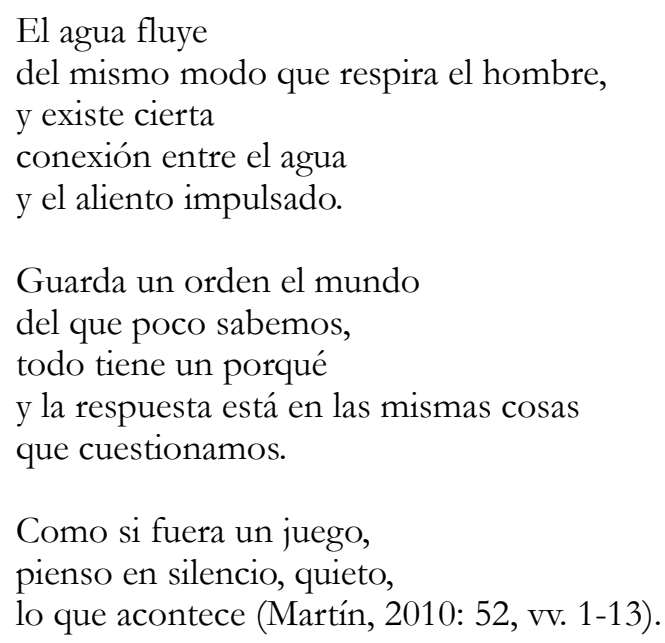

Incluso si sabemos poco del mundo o del porqué de las cosas, para este poema no hay duda que este orden existe. La relación estrecha entre hombre y naturaleza rige esta visión del mundo y la mejor manera de entender el mundo es a través de la reflexión silenciosa, como el "momento detenido" descrito por Krieger.

El tema del silencio aparece también en "La campiña":

Cuánta delicadeza se nos muestra suspendida en el tiempo, levitando apenas un minuto, como si el mundo contuviera su giro por nosotros, y qué extraña manera de ofrecerse tienen las cosas cuando guardo silencio (Martín, 2010: 12, vv. 13-18).

El silencio sigue siendo la mejor condición para captar el orden del mundo, un orden, en este caso, que se ofrece a los seres humanos. El poema "Los espejos del mar" une el silencio y la mirada. Como explica la primera estrofa:

Quienes miren el mar, así, con un silencio dentro de los ojos, con un vacío de las cosas —sin distracción alguna, sólo el mar-, 
podrán decir

que han hallado el tesoro de la vida,

el más preciado don de los mortales (Martín, 2010: 14, vv. 1-8).

Un lenguaje poético que privilegia el silencio y el orden domina en estos tres poemas de El minuto interior y es capaz de transmitir este mundo a sus lectores.

El mirador de piedra presenta una serie de representaciones del Mirador Rodríguez de La Fuente en el Parque Natural de las sierras de Cazorla, Segura y Las Villas. El poema titulado "Cañada de las fuentes" postula una conexión entre la mirada, el yo y la naturaleza. Las dos estrofas del poema presentan el lugar del título y una meditación sobre él. Comencemos con el lugar:

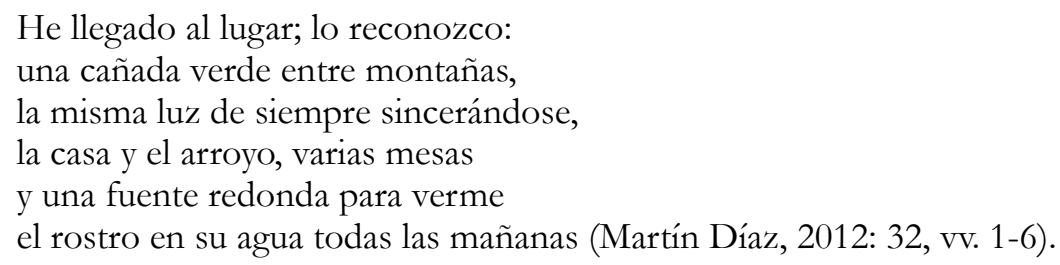

El verdadero eje de esta escena no es el lugar en sí sino el lugar tal como aparece y funciona con respecto al yo que lo observa. El yo llega al lugar y lo reconoce y la "fuente redonda" del lugar existe sólo para que el yo se contemple a sí mismo.

Esta dinámica desigual entre el yo y el entorno natural se explora mediante la pregunta con la que se inicia la segunda estrofa del poema:

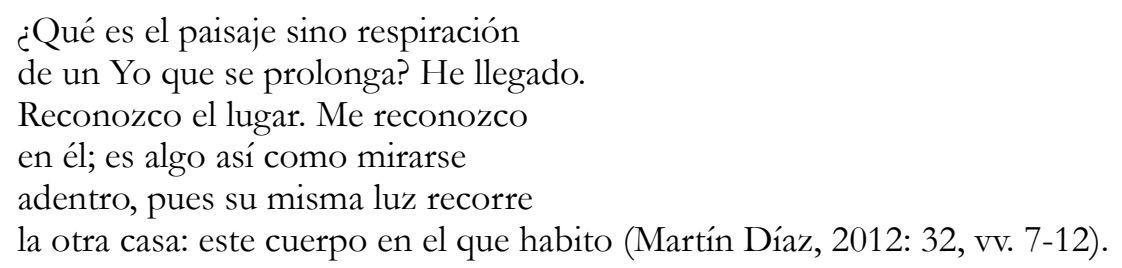

El mundo natural y el paisaje recortado por los ojos y la mirada del yo dependen de éste y de su perspectiva. Una actitud semejante aparece en el poema "Aguacero", el cual declara que "[...] mirar es prolongarse, / reconocer lo externo como propio" (Martín Díaz, 2012: 47, vv. 2-3). En ambos casos el yo y su acto de mirar sirven para subyugar el entorno natural al predominio del yo. Lo que se examina, entonces, es lo que se ve en vez de quién lo ve o cómo lo ve.

Fracturas, el poemario más reciente de Martín Díaz, incluye una mezcla de propuestas estéticas más rica que lo que se observa en sus poemarios anteriores, pero de todos modos lo que predomina en el libro es una idea de orden que ya controla el mundo natural. En su reseña de este poemario, Andrés García Cerdán declara que "[e]n sus poemas nos reconciliamos con la naturaleza, con la inteligencia y con eso que distingue a los grandes poetas: la capacidad de mirar" (García Cerdán, 2016). "Descubrimos con [Martín Díaz]", explica García Cerdán, "que aún tenemos ojos y que el mundo está ahí para que lo miremos y lo hagamos nuestro" (García Cerdán, 2016). 
El poema titulado "Silencio" da por sentada la existencia de un orden basado en el silencio. A partir del apóstrofe el poema describe este silencio antes de usar un mandato que sugiere una manera de mantenerlo y el orden que lo subyace:

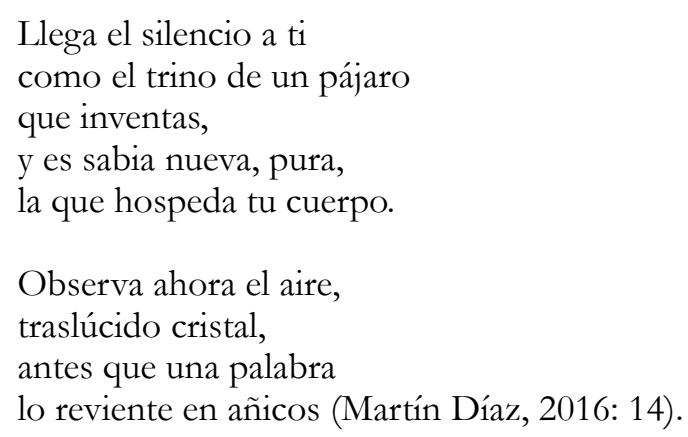

El silencio y su llegada se comparan al "trino de un pájaro / que inventas". Una palabra y su sonido tienen el poder de "reventar en añicos" el aire y el silencio. El lenguaje en este caso se presenta como algo superfluo y hasta dañino, ya que la contemplación silenciosa y sosegada debería ser suficiente para captar la realidad. Esta actitud escéptica hacia el lenguaje se diferencia mucho del escepticismo que muchas veces se asocia con el lenguaje y su capacidad de representar el mundo. Quizá se trate de un escepticismo aún más agudo, ya que se trata de un lenguaje incapaz de representar el mundo pero paradójicamente capaz de destruir el orden ya pleno de la realidad.

$\mathrm{Al}$ igual que sus poemas anteriores el poema breve titulado "Vacío" presenta un enfoque en la naturaleza, pero este poema funciona de una manera diferente de la mayoría de su poesía: "Hay un vacío extraño sobrevolando el llano: / noviembre blanco / en el lomo de un ave que no existe" (Martín Díaz, 2016: 25, vv. 1-3). Esta visión del mundo natural se basa en una parte de una cosa que no existe, y el resultado final es un vacío. En estos poemas vemos una especie de suplemento, ya que emplean el lenguaje para postular que la realidad no necesita el lenguaje para ser representada. La poesía de Rubén Martín Díaz, sea en el caso de los poemas explícitamente ecfrásticos de Arquitectura o sueño o el de sus poemas provenientes de El minuto interior, El mirador de piedra o Fracturas que usan como tema el mundo natural que circunda al yo poético, construye un mundo poético y artístico en el que la elaboración estética va en contra de la representación mimética del mundo. Ya que el campo de la poesía actual también es un territorio cambiante, también hay que reconocer que ningún proyecto estético es monolítico, como nos muestra el caso de "Vacío".

\section{RUBÉN MARTÍN: GRIETAMENTE}

Si el mundo de la poesía de Rubén Martín Díaz está marcado por el orden de un mundo que podemos ver, comprender y controlar, el de Rubén Martín, y en particular el de Sistemas inestables es uno en el que "[j]uegos lingüísticos, elipsis, neologismos y una sintaxis rota configuran un poemario de resonancias textuales diversas que expresan el mundo de fragmentación y confusión en el que vivimos" (García, 2016). El punto de partida que señala Manuel García-“el mundo de fragmentación y confusión en el que vivimos"-no dista mucho del mundo descrito en "Defensa de la poesía", pero la reacción a este mundo fragmentado en la poesía de Martín es 
diferente. Según el propio poeta, " $[\mathrm{u}] \mathrm{n}$ mundo como el de hoy, fragmentado, multiplicado y escindido en millares de imágenes y discursos, no puede plasmarse con un lenguaje lineal, artificiosamente coherente" (García, 2016).

Manuel García busca situar la práctica poética de Martín en un contexto artístico español al declarar que "[c]uando uno empieza a leer tu libro descubre un lenguaje que nos devuelve a las vanguardias y también a los novísimos. ¿De dónde surge la necesidad de acomodar tus pensamientos a ese lenguaje?". García también declara que "en tu poesía hay escepticismo hacia la afectación o hacia las emociones en un sentido postromántico o desde una poesía de la experiencia”. Frente al empeño en situar la poesía de Martín en este contexto, el poeta explica que "no me siento influido directamente por las Vanguardias históricas o el movimiento novísimo-a excepción del Panero de los 70 y 80-, sino por esa corriente subterránea de autores que han perseguido hasta el límite un lenguaje transgresor, oblicuo, huérfano, que por supuesto incluye a muchos poetas anteriores al siglo XX" (García, 2016). Según Martín:

[1]os autores que más me interesan son aquellos que si se aproximan a las vanguardias en determinados recursos es por una necesidad imperiosa de socavar esas raíces que automatizan el pensamiento: el yo, el género artístico, la comunicación autor-receptor, la obra cerrada, los 'temas eternos'. Pienso en escritores como Paul Celan, Chantal Maillard, Leslie Kaplan o Maurice Blanchot; en cineastas como Yoshida Kiju, Andrei Tarkovski o Stan Brakhage; en artistas plásticos como Manuel Millares o Anselm Kiefer. Trato de aprender de todos ellos cómo dar forma a un lenguaje que permita sentir y pensar de otra manera, por canales distintos a los que se nos imponen como correctos y verdaderos (García, 2016).

Con Radiografía del temblor (2007), Martín ganó el Premio de Poesía Andalucía Joven y en 2010, junto con Leopoldo María Panero y Begoña Callejón, publicó Locos de altar. Además de su labor como poeta también ha traducido la poesía de Emily Dickinson (2010) y Jorie Graham (2014) al castellano.

Sistemas inestables, su último libro, está compuesto de cinco secciones: "Contemplación/ En blanco/ El retroceso", "No Mirar / Borradores para un poema en reacción a Anticorps, de Antoine d'Ágata", "Microfisuras / Sedimentos", "Fármaco / Un tríptico", y "No existen mapas / Fragmentos de un cortocircuito / Panorámica". Como explica Rafa Mammos, la tercera sección contiene una serie de representaciones ecfrásticas: “[e]n 'Microfisuras / Sedimentos', Martín reelabora obras (cuadros, canciones, fotos) de otros artistas, las cuales comparten un carácter torturado" (Mammos, 2016: 64). Aunque estos textos no incluyen comentarios estéticos tan explícitos como los que aparecen en Arquitectura o sueño las obras elegidas para estos diálogos revelan mucho en cuanto a la visión estética de Martín. Según el propio poeta, "en Microfisuras / Sedimentos, la sección del libro dedicada al diálogo o contagio con obras artísticas, me he limitado a rendir tributo a aquellas que han provocado una fractura en mi modo de percepción, me han sometido a una escucha otra" (García, 2016).

Es importante reconocer que esta sección de Sistemas inestables establece un diálogo con series de obras en vez de cuadros individuales. Todas estas obras son del siglo XX o XXI y suelen ser abstractas. Este empeño en privilegiar lo abstracto y lo serial exhibe una actitud más a favor de lo experimental, lo fragmentario y lo difuso en vez de representaciones más pulidas y más fáciles de enmarcar. A pesar de la tendencia a privilegiar lo abstracto en estas obras y su 
tratamiento de ellas, dos de estas series se enfocan-a su manera-en figuras y formas humanas. Tanto los "homúnculos" de Manuel Millares como los "anticuerpos" de Antoine d'Ágata se centran en la forma humana y las diversas maneras en las que se pueden fragmentar, deconstruir y representar.

Sin dejar de prestar atención al contenido o al fondo de estas obras, los poemas de Sistemas inestables se enfocan principalmente en su materialidad y su forma, incluyendo las técnicas artísticas que contribuyen a ellas. Cada poema está encabezado por una especie de epígrafe y contiene un párrafo seguido por una lista de palabras. En la mayoría de estos casos esta lista está dividida por algún símbolo tipográfico (“,”, “|”, “_,”, “_”, “/”, ‘””, “:”). En su discusión de esta técnica en su entrevista con Manuel García, Martín explica que:

[e]l uso de signos paralingǘsticos, que aprendí al traducir a Emily Dickinson y Jorie Graham, es una manera de interrumpir el flujo pretendidamente natural del lenguaje, tratarlo como una materia que puede fracturarse para revelar sus sucesivas capas. También un modo de establecer una música visual en la lectura, en tensión y contradicción con la música verbal de la métrica. En cierta forma mi objetivo es componer partituras en las que el lector cumple el rol de intérprete, no de mero oyente (García, 2016).

Una de las obras plásticas con las que dialoga Sistemas inestables es la serie de "Homúnculos" creados por el pintor canario Manuel Millares Sall (1926-1972). Este poema, que lleva como epígrafe "(Manuel Millares, "Homúnculo")", presenta una mezcla de referencias al fondo y la forma de las obras de Millares. El texto está compuesto de frases muy cortas, a veces de una sola palabra y comienza con una alusión al contenido de las obras de Millares, cuando explica que:

Estos muertos. Aún. Respiran. Demasiado (con una frase larga la sintaxis se escabulle por los huecos, anuda, amarra los andrajos, simula un organismo). Los recubro. De arpillera. Y aúno. Con clavos. Separo. Con metralla. La x. Crucifixión. Encrucijada. El ex-stasis. Lo que se queda. Quieto. Afuera. Y dice. Rígido (o grietamente la marca de que hay hombre enterrado, una resina negra ha desollado las paredes del tú, su extremo visceral, impregna el fondo, acaba abriendo

orificio ) perforación ) rotura-ojo ) abismo-boca ) insepultura )

(Martín, 2015: 63).

El yo en este poema parece corresponder al artista y se enfoca en la serie de técnicas que sirven para crear este tipo de obra. El uso estratégico de los paréntesis se destaca en este poema. Además de representar un contraste con la brevedad de las oraciones del texto también presentan una serie de diferentes alternativas en cuanto a lo que la "resina negra" del texto "acaba abriendo". Estas alternativas—“orificio", "perforación", "rotura-ojo", "abismo-boca" e "insepultura"- comparten un enfoque en los huecos.

El poema dedicado a "Anticorps" de Antoine d'Ágata se construye a partir de un juego con la equivalencia. Esta sensación de equivalencia se logra mediante la repetición de la palabra "así" y una serie de dos puntos a lo largo del texto para dividir y juntar los elementos presentados en el poema:

Bajo la inercia : la infección, el desdibujamiento de todas las fronteras : hay una escala de umbrales sucesivos, arpegiando lo mirable, lo sentible : todo abierto, todo esponja, más 
vacío que materia : así estas manos que son piernas que son bocas que son sexos : así este nudo de carne en resistencia, todo es pasivo en la latitud del cuerpo y de este modo oculto, sincopado, sobrevive : frente a un mundo sin luz, otro sin órganos : la mutación como salida, como entrada : no puedes no mirar, no puedes no sentir :

el movimiento : el contagio : un esguince de mirada : una torsión : irreversible :

(Martín, 2015: 65).

El fondo y la forma de la serie de d'Ágata se reflejan en el poema de Martín. El poema presenta una tensión entre inercia y movimiento, separación y unión y plantea la "mutación" como concepto clave y ambiguo, ya que es descrita "como salida, como entrada". La serie de equivalencias presentadas a lo largo del poema se extiende también a este elemento en particular mediante el uso de la coma.

Como fue el caso también en el poema dedicado a la obra de Millares, la segunda parte de este poema sirve como una especie de continuación de la primera. Al igual que en el poema anterior también parece presentar una serie de opciones o alternativas. Estas opciones parecen ser ejemplos de lo que no se puede no mirar o no sentir, como afirma el último elemento que aparece en la primera parte del poema.

Lo que no queda tan claro, sin embargo, es la relación entre este último elemento de la primera parte del poema y los demás. Aunque es cierto que se puede trazar cierta lógica en la serie de elementos separados por los dos puntos, gracias a palabras como "bajo", "hay" o "así", esta lógica es mucho menos clara a partir del séptimo elemento ("frente a un mundo sin luz, otro sin órganos"). No sabemos, entonces, qué elementos o factores hacen que no se pueda no mirar y/o no sentir "el movimiento : el contagio : un esguince de mirada : una torsión : irreversible :". ¿Son todas las cosas que aparecen en la primera parte del poema en una especie de masa sin jerarquía o lógica? ¿O hay una lógica detrás de esta serie de elementos que apuntan a la interrelación de cuerpos?

Un poema proveniente de la segunda sección del libro, "No Mirar / Borradores para un poema en reacción a Anticorps, de Antoine d'Ágata", también establece un diálogo con esta serie y presenta una visión compleja de la relación entre el yo, su mirada y lo que ve. Como sucede también en otros poemas de esta colección, éste tacha algunas palabras y el enfoque del poema, incluso cuando está tachada, es la palabra yo. Este yo es un yo abstraído que dialoga con el concepto de un yo en vez de un yo concreto. Según el texto,

El yo:- el yo es un racimo de miradas: un yo es detener el rostro en el fluido elástico de un gesto, una mirada: pero estos seres, yo, no tienen rostro, el rostro cae en el instante en el que das un paso y no hay un suelo, no hay un eco un negativo que sustente nuestro paso o le sirva de reverso, mi rostro, su caída, mi mirada que se aleja desgarrando el cuerpo entero de una piel, tu recuerdo de algo semejante a un suelo gira y pierde el equilibrio, pierde nombre, se hace líquido, se hace, se disforma en sedimentos de otros nombres que cayeron, enfría sus estratos de vértigo candente, la caída se detiene

y te mira a los ojos

(Martín, 2015: 45). 
En vez de ser un ente fijo y estable, un yo según este texto es múltiple y cambiante. Además de ser más ambigua la relación entre el yo y lo que ve a través de la mirada no se basa en la superioridad del ser humano.

La mirada es el enfoque de un poema que proviene de la primera sección del libro ("Contemplación/ En blanco/ El retroceso") y el acto de mirar en este caso conduce a una especie de pérdida de identidad. Esta sección está compuesta de una serie de diez poemas numerados con fragmentos de diario intercalados. El tercer poema numerado consiste en una sola oración dividida en varias partes. La exploración de la mirada se enfoca en "el acto de mirar" y según la voz poética:

Hay que entrar en el acto de mirar esta pared igual que se penetra

por vez primera un templo,

como quien entra en su mirada para acercarse a un cuadro que se amó de antemano, a contraliento, (Martín 2015: 14)

El tono sagrado asociado con este acto de mirar continúa en el poema y se conecta con elementos claramente religiosos:

hay que entrar mudo, entrar sombra, como espina

en la frente de un mesías en el que nadie cree (Martín 2015: 14)

Si en este trozo del poema se presentan ejemplos de la ausencia mediante la presencia ("entrar mudo, entrar sombra"), en el próximo trozo se presencia una ausencia más explícita en el modo de entrar:

entrar sin huesos ni memorias ni templos ni paredes

anteriores, avanzar líquido

y medusa, irreversible, (Martín 2015: 14)

El resto del poema utiliza gerundios combinados con la negación de ser y/o estar para describir implícitamente el modo de entrar en el acto de mirar:

simulando no estar, los pies sobre las ascuas

de todo lo mirado,

transpirando no ser, negando cada paso y cada pensamiento,

los pensamientos como dedos que apagan

una idea, la quemadura es suave y con ella se da tacto a la noche, a la pobreza, a la inmovilidad (Martín 2015: 14).

En vez de presentar la mirada como un acto sencillo este poema eleva esta acción a la vez que la desacraliza. Mientras se adentra más en la descripción del acto de mirar se aleja más de una visión sencilla de la mirada, además de una visión que da por sentada la integridad y la entereza del yo o ser humano que mira. Este extrañamiento del yo y el mecanismo que emplea para 
comprender el mundo que habita enfatizan la ambigüedad, la complejidad y la incertidumbre frente a una concepción más directa de nuestra relación con el mundo.

El primer poema de esta sección nos lleva al terreno acotado por la "Defensa de la poesía" que acompaña la antología Poesía ante la incertidumbre, al declarar que:

No hay incertidumbre: hay incerteza,

la incertidumbre avanza, tantea, su pulso se acelera cuando camina a oscuras y tropieza una silla. Ajena al quién, se aferra al yo. Nada menos oscuro

que esta habitación: esta deshabitación. La incerteza es estática, no busca, no exige, la idea de una silla se detiene en un umbral en el que permanece inconcebible,

abortada e irrisoria su función, sus cuatro patas, la madera retrocede a la materia, se acopla en posiciones-máscara, en posiciones-nudo, oráculo de astillas,

caja de disonancia. La mirada de nadie

en la pared. Sin dejar rastro. No:

sin dejar rastro. Ni sombra

ni residuo. Solo pared, y el infinito ahora (Martín 2015: 10-11).

Este poema plantea una tensión sugerente entre la incertidumbre y la incerteza, entre distintas formas y maneras de enfrentarse a la realidad y al mundo. Aunque la escritura de Rubén Martín explora el mismo terreno conceptual que exploran otros poetas, conceptos como la mirada, el cuerpo humano y el yo que mira este cuerpo se entienden de otra manera en los poemas de Sistemas inestables.

\section{UN ALTO EN EL CAMINO}

La práctica poética de estos dos escritores españoles emplea diferentes maneras de posicionarse frente a la imposibilidad de la écfrasis y las limitaciones de la mímesis. La poesía de Rubén Martín Díaz exhibe una apuesta por lo visible, lo humano y la capacidad del lenguaje de representar lo real y lo visible mediante la expresión mínima. Para Martín Díaz el lenguaje y las palabras pueden destruir la perfección de la naturaleza y su orden y como resultado es mejor evitar la elaboración discursiva de las descripciones poéticas y dejar que lo natural y su transparencia hablen con voz propia. Para Rubén Martín Díaz la naturaleza tiene una presencia $\tan$ fuerte que no hay ninguna imposibilidad con respecto a la écfrasis y la mímesis. El centro de este sistema elaborado por sus poemas es el hombre que observa este entorno natural y lo presenta al lector. Esta práctica se basa, entonces, en una visión clara y transparente de la realidad y la naturaleza filtrada por la perspectiva de un ser humano testigo de esta presencia transparente.

La poesía de Rubén Martín también tiene como centro la relación entre el ser humano, el mundo natural y el lenguaje, pero a diferencia de la escritura de Rubén Martín Díaz, Martín concibe esta relación como una dinámica más conflictiva. En vez de basarse en la presencia, 
transparencia y asequibilidad de lo natural y la capacidad del lenguaje de comunicar esta realidad a un lector, los textos de Rubén Martín se basan en la imposibilidad de semejante esfuerzo. En vez de ver esta imposibilidad como un impedimento o limitación, tanto los textos explícitamente ecfrásticos como los textos no ecfrásticos de Rubén Martín exploran la ambigüedad y la complejidad de esta dinámica y su valor para el proyecto de entender el papel que juega lo humano frente al estímulo complejo y multiforme del mundo que sirve como su entorno. En este caso no se trata ni de una esperanza ecfrástica ni de un miedo ecfrástico, sino de una visión de la écfrasis-y la poesía — que acepta y da por sentadas la complejidad del mundo y la realidad y la imposibilidad de representarlo. Esta manera de concebir la écfrasis se despoja del bagaje mimético que acompaña otras concepciones de la mímesis.

Las actitudes hacia el lenguaje, la realidad y la relación compleja entre ellos que se observan en la obra de Rubén Martín Díaz y Rubén Martín aparecen también en la poesía de otros poetas contemporáneos. Una visión más optimista del lenguaje poético y su capacidad de captar la realidad se encuentra en la obra de poetas como Fernando Valverde (Granada, 1980), Pablo Núñez (Langreo, Asturias, 1980), Andrés Catalán (Salamanca, 1983) y Constantino Molina Monteagudo (Albacete, 1985), mientras que una visión más escéptica y una práctica poética más experimental se observan en la obra de poetas como Ana Gorría (Barcelona, 1979), Ignacio Miranda (Madrid, 1981), Alejandra Vanessa (Córdoba, 1981), María Salgado (Madrid, 1984), Lola Nieto (Barcelona, 1985), María Eugenia Motilla (Madrid, 1988) y Le Corbeau (Víctor Martínez Rodríguez, Madrid, 1995).

$\mathrm{Al}$ examinar la poesía de cualquiera de estos escritores es necesario tener en cuenta la complejidad del mundo contemporáneo en el que vivimos y el tipo de actitud que se presenta en cada texto con respecto a la relación entre ser humano, realidad y lenguaje. También es importante plantear preguntas como las siguientes: ¿Qué tipos de aproximaciones se emplean hoy en día? ¿Cómo dialogan con otras formas de acercarse a la realidad y la escritura? ¿Tienen el mismo grado de visibilidad estas propuestas de escritura, o circulan en un espacio discursivo en el que ciertas aproximaciones son más visibles y tienen más peso que otras?

Lejos de ser un espacio y entorno despolitizado en el que todo vale y toda voz tiene la misma posibilidad de llegar a un/a lector/a, el ambiente poético español actual está construido a partir de una tensión entre poesía figurativa y no figurativa y esta tensión ha dominado durante la mayoría del siglo XX. Para tener una imagen más clara, rica y plena de la producción poética española actual es importante reconocer la diversidad estética de las muchas propuestas de escritura que circulan en este momento y prestar atención a qué se dice en la poesía, al igual que cómo y desde dónde se dice, en vez de sólo prestar atención a quién lo dice. Los poemas de Rubén Martín Díaz y Rubén Martín-sean ecfrásticos o no-presentan dos visiones diferentes de la poesía española reciente y su relación con el lenguaje y la realidad y demuestran que tener el mismo punto de partida — un mundo fragmentado-no significa que toda aproximación a este mundo tenga que seguir las mismas pautas. Acercarnos a esta producción poética actual sin los prejuicios de debates poéticos o críticos anteriores nos ayudará a apreciar y dar cuenta del territorio estético y conceptual que ocupa la poesía española actual y también nos ayudará a apreciar y rescatar propuestas de escritura del pasado que han sido olvidadas o silenciadas. 


\section{BIBLIOGRAFÍA}

"Defensa de la poesía". (2011). Poesía ante la incertidumbre. Antología (Nuevos poetas en español). Madrid: Visor: 7-12.

Dickinson, Emily (2010). Poemas a la muerte. Trad. Rubén Martín. Velilla de San Antonio (Madrid): Bartleby Editores.

Floriano, Miguel y Rivero Machina, Antonio (2016). "Epílogo". Floriano, Miguel y Rivero Machina, Antonio (eds.). Nacer en otro tiempo. Antología de la joven poesía española. Sevilla: Renacimiento: 223-228.

GARCÍA, Manuel. "Entrevista al poeta Rubén Martín tras publicar su poemario 'Sistemas inestables" lecturaobligada (2016).

GARCía CERDÁN, Andrés. “El mirlo blanco: Rubén Martín Díaz”. ABC Toledo 21-4-2016.

Graham, Jorie (2014). Rompiente. Trad. Rubén Martín. Velilla de San Antonio (Madrid): Bartleby Editores.

LANZ, Juan José (2012). "Dibujo de la muerte: écfrasis e imitación artística en la poesía de Guillermo Carnero". DíAz DE CASTRO, Francisco y DEL Olmo iturRiarTe, Almudena (eds.). Écfrasis e imitación artística en la poesía hispánica contemporánea: Diez propuestas. Sevilla: Renacimiento: 111-36.

Mammos, Rafa. “'Sistemas inestables', de Rubén Martín”. Quimera. Revista de literatura 388 (2016): 64.

MARTín, Rubén (2007). Radiografía del temblor. Sevilla: Renacimiento.

MARTÍN, Rubén (2010). El minuto interior. Madrid: Ediciones Rialp.

MARTín, Rubén (2015). Sistemas inestables. Velilla de San Antonio (Madrid): Bartleby Editores.

Martín, Rubén, Callejón, Begoña y Panero, Leopoldo María (2010). Locos de altar. Granada: Editorial Alea Blanca.

MARTín DíAz, Rubén (2012). El mirador de piedra. Madrid: Visor.

MARTín DíAZ, Rubén (2015). Arquitectura o sueño. Sevilla: Ediciones de La Isla de Siltolá.

MARTín DíAZ, Rubén (2016). Fracturas. Albacete: Nausícaä.

MitCheLl, W. J. T. (2009). Teoría de la imagen: Ensayos sobre representación verbal y visual. Trad. Yaiza Hernández Velázquez. Madrid: Akal.

Morán Rodríguez, Carmen (2012). "Escribir con ceniza dibujos de ceniza: Ashes to ashes, de Ada Salas y Jesús Palencia”. DíAz DE CASTro, Francisco y DEL Olmo iturRiarTe, Almudena (eds.). Écfrasis e imitación artística en la poesía hispánica contemporánea: Diez. propuestas. Sevilla: Renacimiento: $159-82$.

Morante, José Luis (2016). "Prólogo". Morante, José Luis (ed.). Re-generación. Antología de poesía española (2000-2015). Granada: Valparaíso Ediciones: 11-41. 
PERsin, Margaret H. (1997). Getting the Picture: The Ekphrastic Principle in Twentieth-Century Spanish Poetry. Lewisburg: Bucknell University Press.

TALENS, Jenaro (1989). De la publicidad como fuente historiográfica. La generación poética española de 1970. Valencia: Episteme. 